\title{
GPRTVN - Processing ground penetrating radar data software
}

\author{
Nguyen Thanh Van, Nguyen Van Thuan, Dang Hoai Trung, Vo Minh Triet, Vo Nguyen Nhu Lieu
}

\begin{abstract}
Designing and mapping underground construction works have been doing for years to meet urgent demands in urbanization process. In this field, Ground Penetrating Radar (GPR) method has shown many advantages in determining underground structures. However, our country has almost no processing program that meets demands of processing and interpretation GPR data. This paper introduced GPRTVN processing program which was the research result of the Department of Geophysics for years. This program could process data of many present GPR equipments and quickly provide cross sections of existing underground constructions. It would be very useful for construction and building investigation companies in Vietnam.
\end{abstract}

Tù khóa-Minimum entropy, energy, migration, processing GPR data

\section{INTRODUCTION}

G PRTVN, the first GPR data processing software in Vietnam, was designed by the Department of Geophysics, VNUHCM University of Science. The user interface of GPRTVN was designed for the ease of use with all controls and options available on the window (Fig. 1). The main window was divided into several menus. The first menu was located on the top left of window. This software could read multiple data formats: *.dt, *.dt1, *.rd3, *.dzt and *.sgy, measured from many present GPR equipments in the world.

Received 29-05-2017; Accepted 10-10-2018; Published 2011-2018

Nguyen Thanh Van, Nguyen Van Thuan, Dang Hoai Trung, Vo Minh Triet, Vo Nguyen Nhu Lieu - University of Science, VNU-HCM

*Email:nvthuan@hcmus.edu.vn

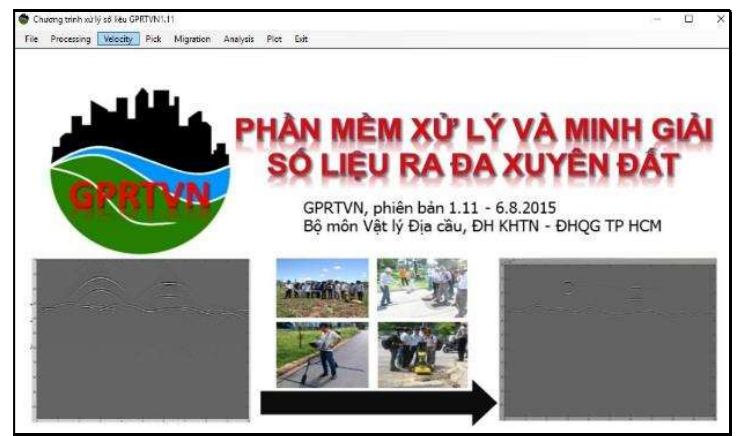

Fig. 1. GPRTVN software

The software could execute all GPR data processing steps. The first step was the time correction, noise reduction and gain [5]. The second one was to determine the electromagnetic wave velocity by migration methods or hyperbolic diffraction. The last one is to calculate the size, depth and showing 2D or 3D cross sections of objects.

\section{MATERIAL AND METHOD}

\section{Noise filtering and amplification}

Noise filtering and amplification were two extremely important steps in this data processing.

\section{Noise filtering}

Noise was created by the random electron motion. This was commonly caused by external noise sources, equipment problems, or traversing too fast if the odometer was used. Filtering was generally applied to the data to remove the sytem noise for the visual quality improvement of the data [1]. Our GPRTVN software had a lot of noise filters like: DC remove, frequency filter, background, flat reflect filter, median filter...

\section{Amplification}

GPR signals could be rapidly attenuated during the propagation into the ground. The related amplitude could be recovered by applying the gain function to compensate the propagation losses at higher depths. The purpose of this gain was to correct the wave front divergence - decay in 
amplitudes caused by geometric spreading of electromagnetic waves [1]. There were two gain filters in our sofware: the gain function and the AGC.

\section{Migration methods}

In seismic, migration methods were used to move dipping reflections to their true positions and collapse diffraction [9]. The migration was done by extrapolating recorded wave field on the ground
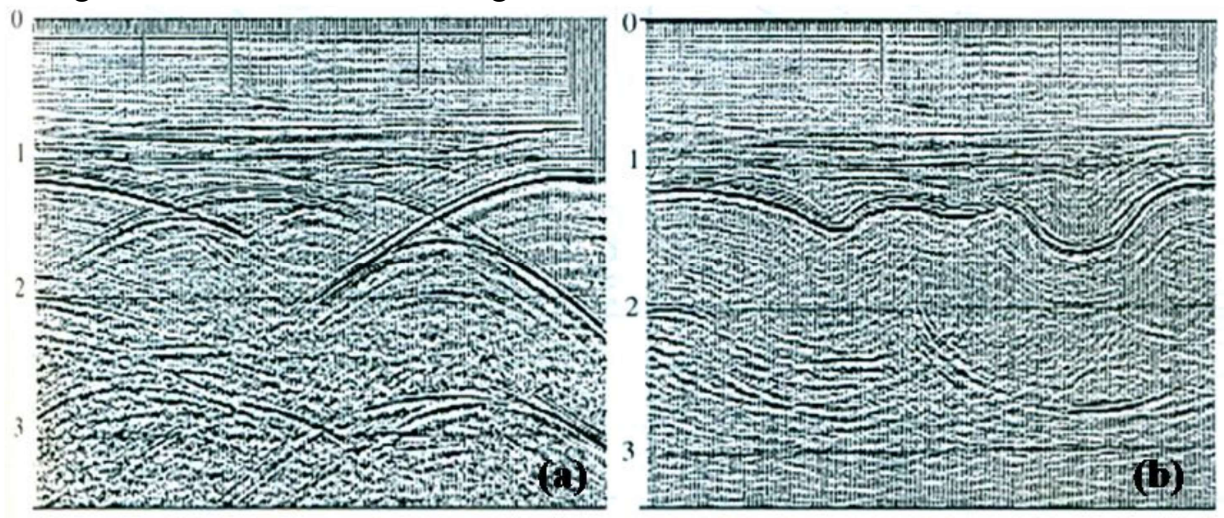
physical properties of the rock (Fig. 2).

Fig. 2. (A) Seismic section before migration; (B) Seismic section after migration

Decisive factor in the success of migration was the accuracy of velocity model in media. In fact, the wave velocity was very complex, it changes on both vertical and horizontal directions. The more complex velocity was the more difficult migration had. Therefore, selecting migration method suitable for each geologic media played an important role in improving the quality of the migrated section.

GPR method and seismic method had a number of similarities: the principle of operation was based on the reflection of waves, the operator and the two variables on the wave equation played the same role (Szaraniec, 1976, 1979; Ursin, 1983; Lee and others, 1987, Zhdanov, 1988) [3,4]. The similaritiy of the geometrical characteristics between two such wave fields could be exploited in the processing of data. Therefore, many methods in seismic could be applied directly to processing GPR data if they had the same type of arranging transceivers [6-8].

To apply poststack migration, we had to use zero-offset data. Normally, when surveying in the city, GPR data were recorded by common offset type by shielded antennas, thus the deviation caused by distance from transmitter and receiver was really small (about $10-20 \mathrm{~cm}$ ). The ratio between correction time and travel time was less than $1-2 \%$, so we could neglect the correction to reflecting points wave field at the depth. Hence the scattered wave field recorded from reflecting points of converge. Amplitude, shape and phase of migrated image related to the reflection coefficient of reflecting boundary. Therefore, migration showed not only the geologic information but also the reflection coefficient at the boundary and

without affecting migration result. Therefore, $\mathrm{CO}$ section in GPR was considered zero-offset section in seismic.

The migration in GPR and the migration in seismic had the same purpose. They all helped us to know the information about the shallow reflecting the geologic structure, defining the true velocity of media, shape and size of object, putting boundary into its real position. The migration is substantially solving inverse problem in GPR.

Mathematically, the migration was essentially to solve the problem of the mechanical wave propagation equation. In practical data processing, migration is the conducted in computer systems and programming software, which required the use of algorithms to approximate the roots of the wave equations. Each philosophy of migration method lead to a certain type of algorithm. There were three most popular algorithm methods applied to migration: the energy summation of diffraction wave field - Kirchhoff migration, the 2-D Fourier transformation - F-K Migration, the wave field downward continuation - Finite Difference migration (FD) and Phase Shift Plus Interpolation migration (PSPI).

\section{Entropy and energy}

GPR sections displayed on the computer was obtained by digital methods in GPR equipments. 
The most common image representation was the raster pattern, in which the image was represented as a matrix of points, with the size (mxn) [2].

$$
X=\left[\begin{array}{cccc}
x_{11} & x_{12} & \ldots & x_{1 n} \\
x_{21} & x_{22} & \ldots & x_{2 n} \\
: & : & : & : \\
x_{m 1} & x_{m 2} & \ldots & x_{m n}
\end{array}\right]
$$

The elements in matrix $X$ corresponded to pixel images and had the value as recorded GPR amplitude. Therefore, we could apply entropy standard in image processing to GPR data. To overcome the limitations in the entropy formula of Shanon (1948), the entropy of a X image was approximated by formula [3]:

$$
E(X)=\sum_{j=1}^{n}\left\{\frac{\sum_{i=1}^{m} x_{i j}^{4}}{\left[\sum_{i=1}^{m} x_{i j}^{2}\right]}\right\}
$$

According to the definition, the maximum value of entropy was 1 for the single trace data set when the data contained only a peak pulse with singleunit amplitude, as to the $\mathrm{N}$ trace sets, the value was N. In terms of an image, the greater its entropy was, the more confusing the image target point was. Vice versa, minimizing the entropy of image after migration processing could optimize the focus effect. So the effect of migration processing could be evaluated by minimum entropy technique in order to make the focus effect optimal.

On the other hand, energy of $\mathrm{X}$ image was defined as [8]:

$$
D(j)=\sum_{j=1}^{m} x_{\mathrm{ij}}^{2} ; \mathrm{j}=1,2, \ldots, \mathrm{n}
$$

(3)

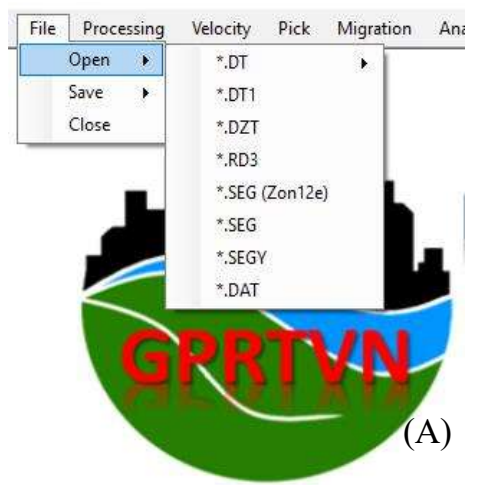

According to the physical principle, a buried object would create more reflection than surrounding media, so that its signal would be increased. However, the recognition of energy was easily affected by the noise. Therefore, we had to remove noise in data by moving the average and the arithmetic average method before calculating the energy of signal.

The combination of entropy and energy standard to optimize the migration algorithm is implemented as follow:

- Step 1: processing GPR data through basic steps: time correction, noise reducing and amplification to highlight the important signal.

- Step 2: migrating GPR data with possible velocity range to calculate the entropy and energy value.

- Step 3: defining the minimum entropy or maximum energy value to determine exactly the electromagnetic wave velocity of media upper of the object.

\section{RESULT AND DISCUSSION}

\section{Defining underground electric cable}

As soon as the program started, the user clicked File > Open and chose data formats: *.dt, *.dt1, *.rd3, *.dzt and *.sgy (Fig. 3a). A window suddenly appeared, the user clicked on a folder name and scaned the selected data files. Fig. $3 b$ showed the raw GPR section of line 26 that was an transverse line passing through Hoa Hao street, District 5, HCM City.

Fig. 3. GPR section of T26: (a). File Menu Item; (b). Recorded section;

All filters available within the Processing group (Fig. 4a), user chose DC remove, dewow, background, $\mathrm{AGC}$ and gained function in the
GPRTVN software to process data. After processing, we had the image as Fig. 4B. 


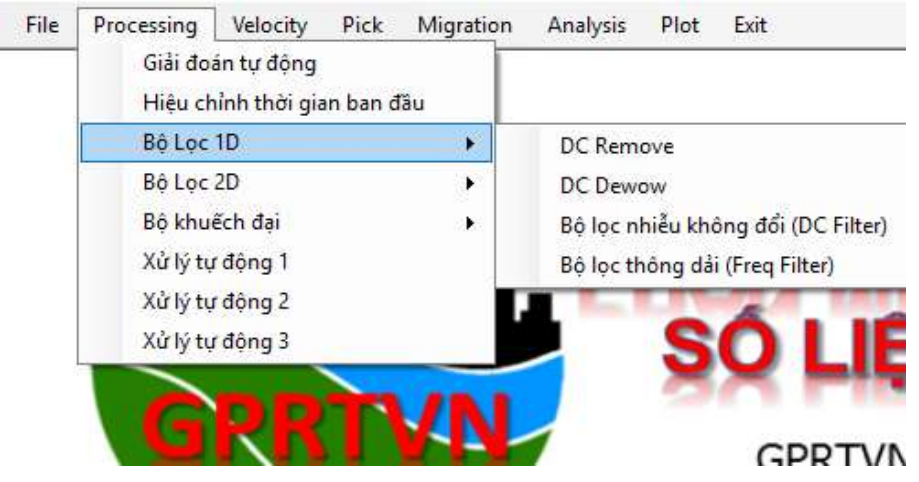

(A)

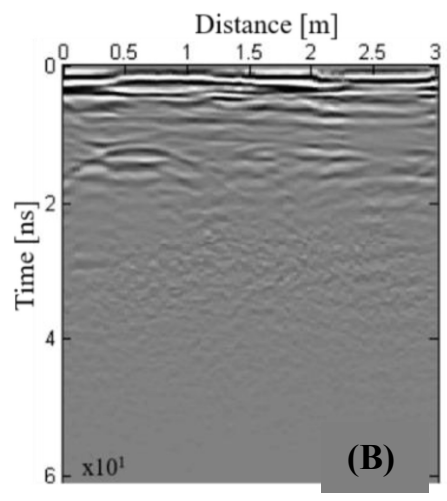

Fig. 4. GPR section of T26: (A). Processing MenuItem; (B). Noise reduction section

Using both entropy and energy standard in Velocity toolbar, we input the velocity range from $0.06 \mathrm{~m} / \mathrm{ns}$ to $0.14 \mathrm{~m} / \mathrm{ns}$ (skip factor $0.001 \mathrm{~m} / \mathrm{ns}$ ).

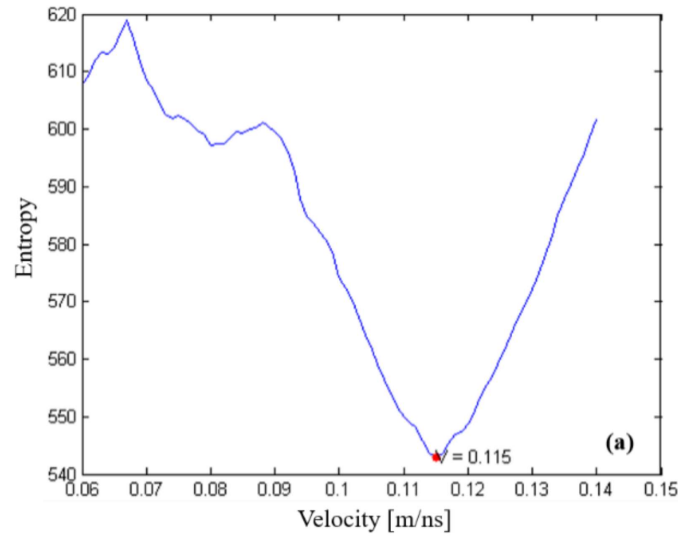

The entropy and energy diagram were shown as Fig. 5.

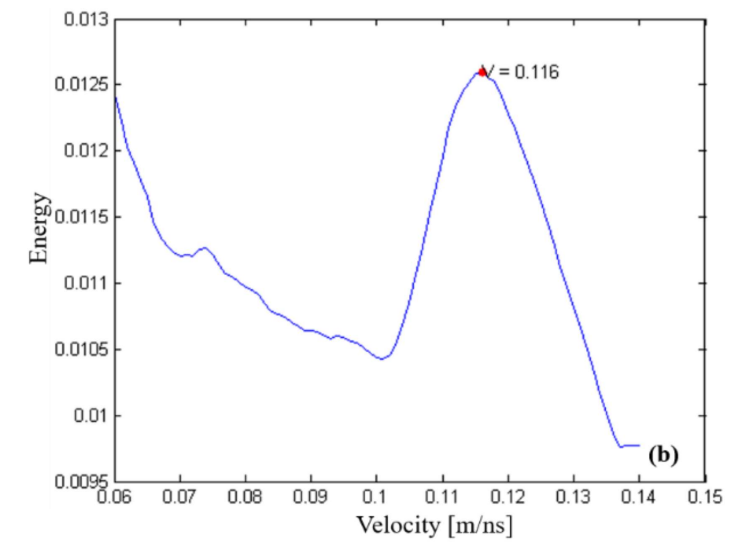

Fig. 5. (A). Entropy diagram; (B). Energy diagram

According to the entropy diagram, the propagation velocity was $0,115 \mathrm{~m} / \mathrm{ns}$. This result was consistent with the result from energy diagram because of the small error, just $0.001 \mathrm{~m} / \mathrm{ns}$. Migrating T26 by using this value, we obtained the results as Fig. 6a. Using Analysis toolbar, we determined that the electric cable was buried at the position $0.599 \mathrm{~m}$ and had the size and depth: 0.11 $\mathrm{m}$ and $0.673 \mathrm{~m}$. This calculated size was consistent with priori information $(0.1 \mathrm{~m})$. The error was just $0,01 \mathrm{~m}$. Calculation results were represented as 3D section. It shows the extension of the pipe as Fig. $6 \mathrm{~b}$.

\section{Establishing underground structure map (water supply pipe)}

Data are measured at site Number 5, Alley 85, Nguyen Hong Street by the Detector Duo equipment with two shielded antennas $250 \mathrm{MHz}$ and $700 \mathrm{MHz}$. The priori information from
Wadeco Company showed that there was a supply water pipe with the size of $\Phi=0.2 \mathrm{~m}$ and at $3.0 \mathrm{~m}$ from the edge of the pavement.

The site Number 5 had the size $2 \times 3 \mathrm{~m}^{2}$. It concluded two lines along T9, T12 and two lines across Nguyen Hong Street T10, T11 (Fig. 7). Using GPRTVN software, we had the results:

Two cross lines $\mathrm{T} 10$ and $\mathrm{T} 11$ had two hyperbolic signals at the positions of $0.5 \mathrm{~m}$ and $1.58 \mathrm{~m}$ (Fig. 8). Because these two lines were parallel and separated by $2 \mathrm{~m}$, we could see the pipeline extended along Nguyen Hong street. 

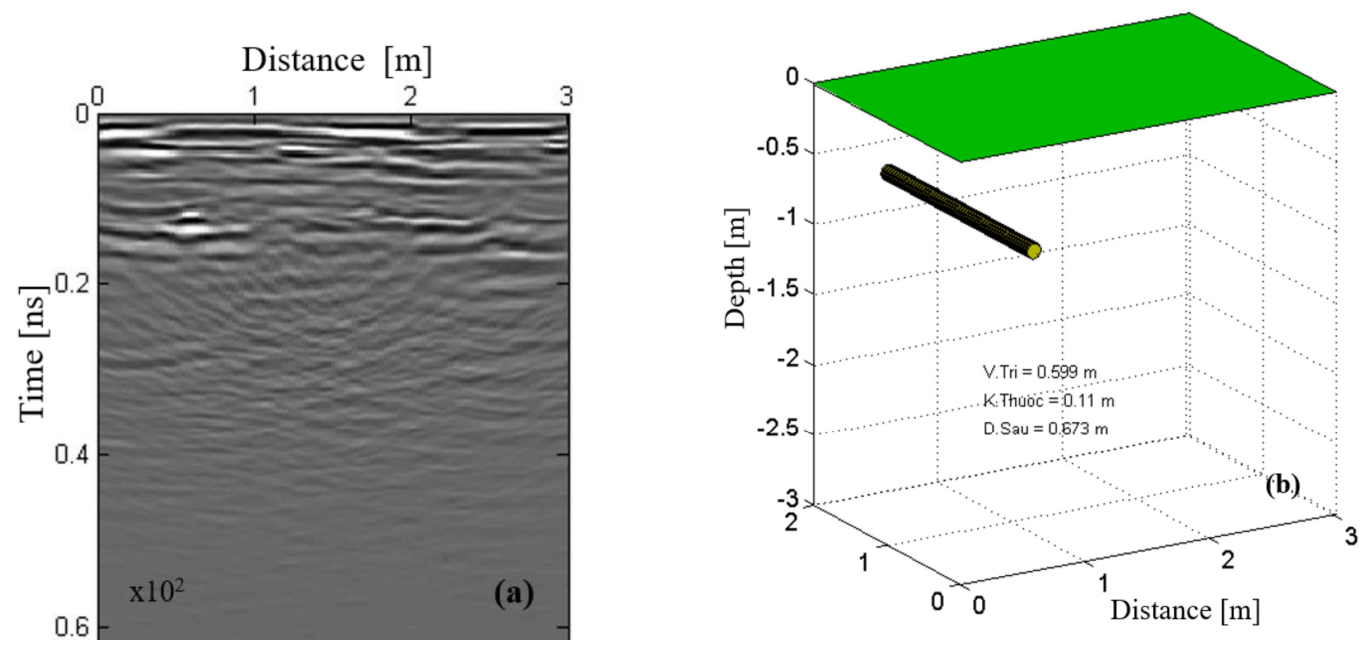

Fig. 6. (A). Migration section; (B). 3D section

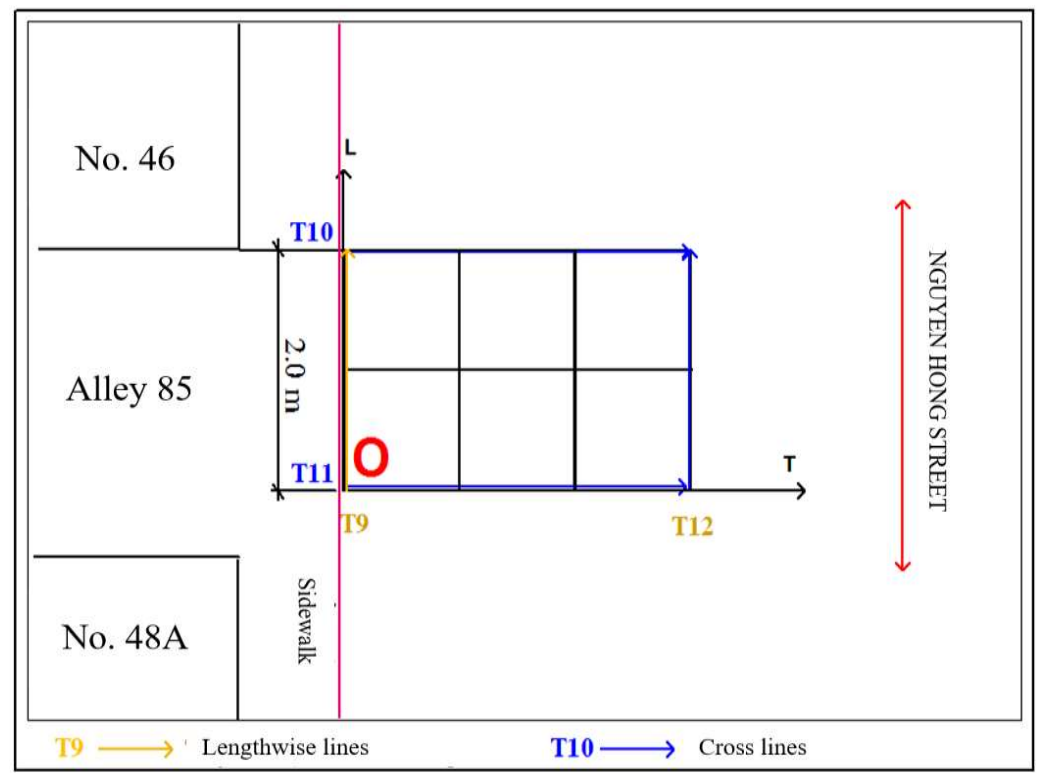

Fig. 7. GPR measuring path at site Number 5
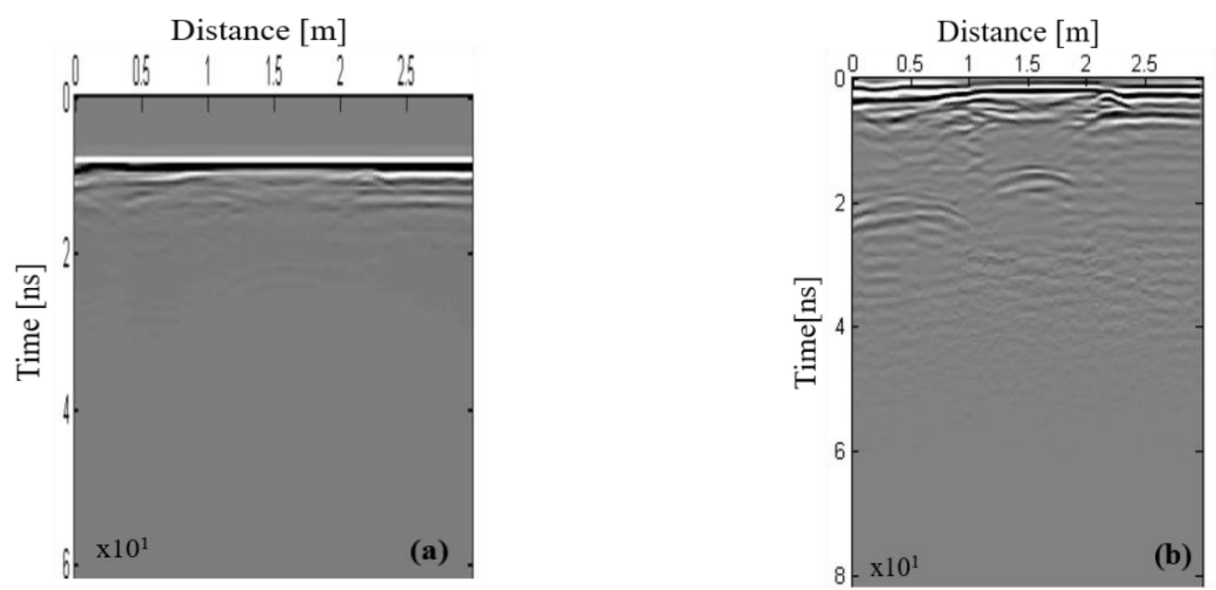

Fig. 8. GPR section: (A). Recorded section; (B). Noise reduction and amplification section 
Using GPRTVN software, the size and depth of underground construction were calculated as follow:

Hyperbola 1: inputing possible velocity range from $0.06 \mathrm{~m} / \mathrm{ns}$ to $0.12 \mathrm{~m} / \mathrm{ns}$, the energy diagram showed that the velocity of media was $0.103 \mathrm{~m} / \mathrm{ns}$ (Fig. 9a). Migrating T10 (Fig. 9b), we could

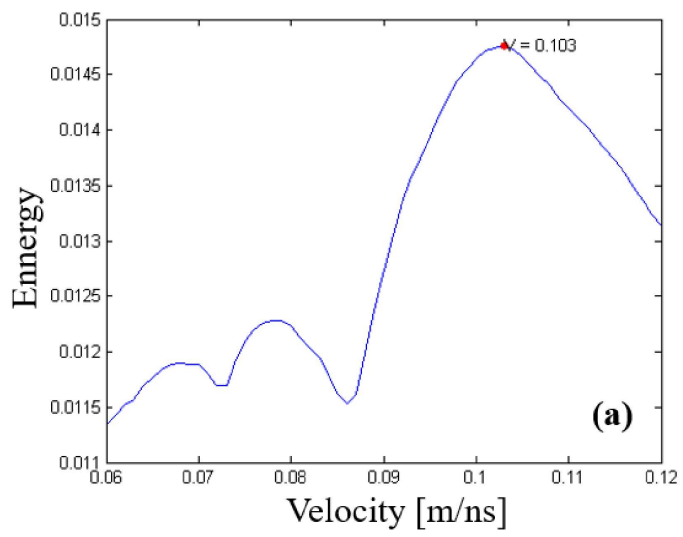

calculate the size and depth of the object: $0.152 \mathrm{~m}$ and $1.04 \mathrm{~m}$ (Fig. 11a). Comparing with the priori information, this object was not the water supply pipe $\Phi=0.2 \mathrm{~m}$. This was a new underground work that had not been updated into underground map of Wadeco Company.

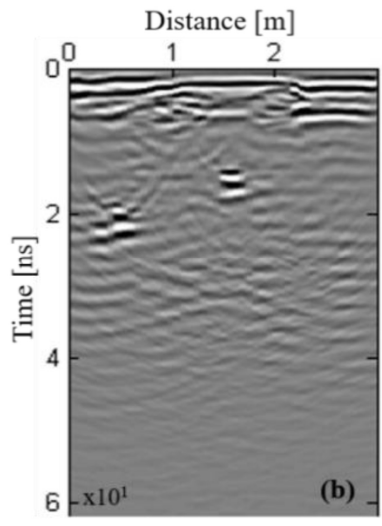

Fig. 9. Hyperbola 1: (a). Energy diagram; (b). Migration section

Hyperbola 2: Similar to hyperbola 1, the calculated velocity was $0.091 \mathrm{~m} / \mathrm{ns}$ (Fig. 10A). This result showed that the electromagnetic wave velocity of media changed not only vertically but also horizontally. On the same line survey, the velocity at each position would not be the same.

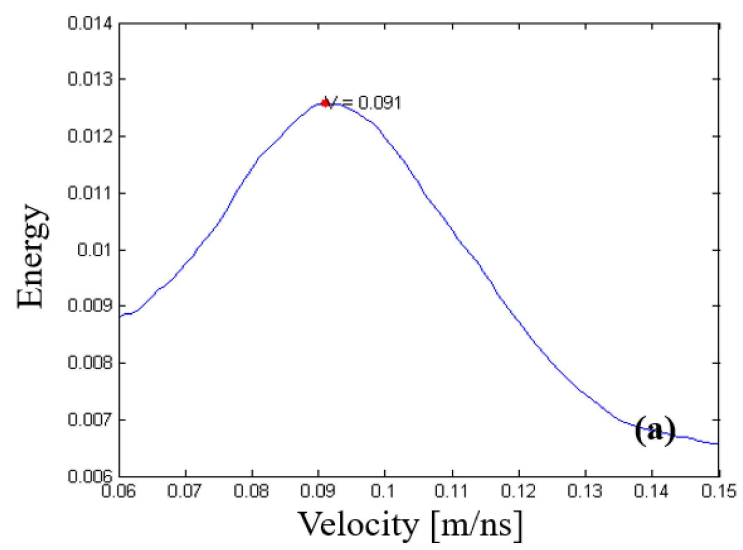

Migrating T10 (Fig. 10B), we could calculate the size and depth of object: $0.195 \mathrm{~m}$ and $0.722 \mathrm{~m}$ (Fig. 11A). This was the water supply pipe $\Phi=0.2$ $\mathrm{m}$ defined in the underground map of Wadeco company.

Fig. 10. Hyperbola 2: (a). Energy diagram; (b). Migration section

Two lengthwise lines T9 and T12 did not have hyperbolic signal. This meant that there were no

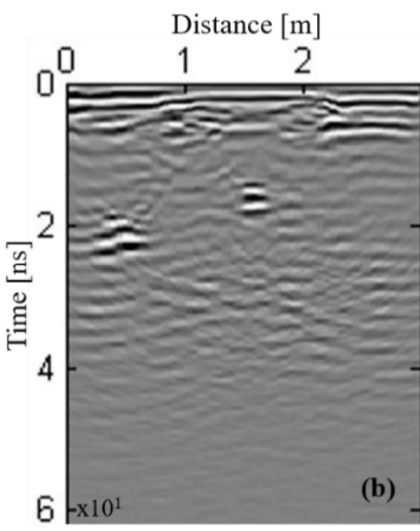

underground works across the Nguyen Hong street 

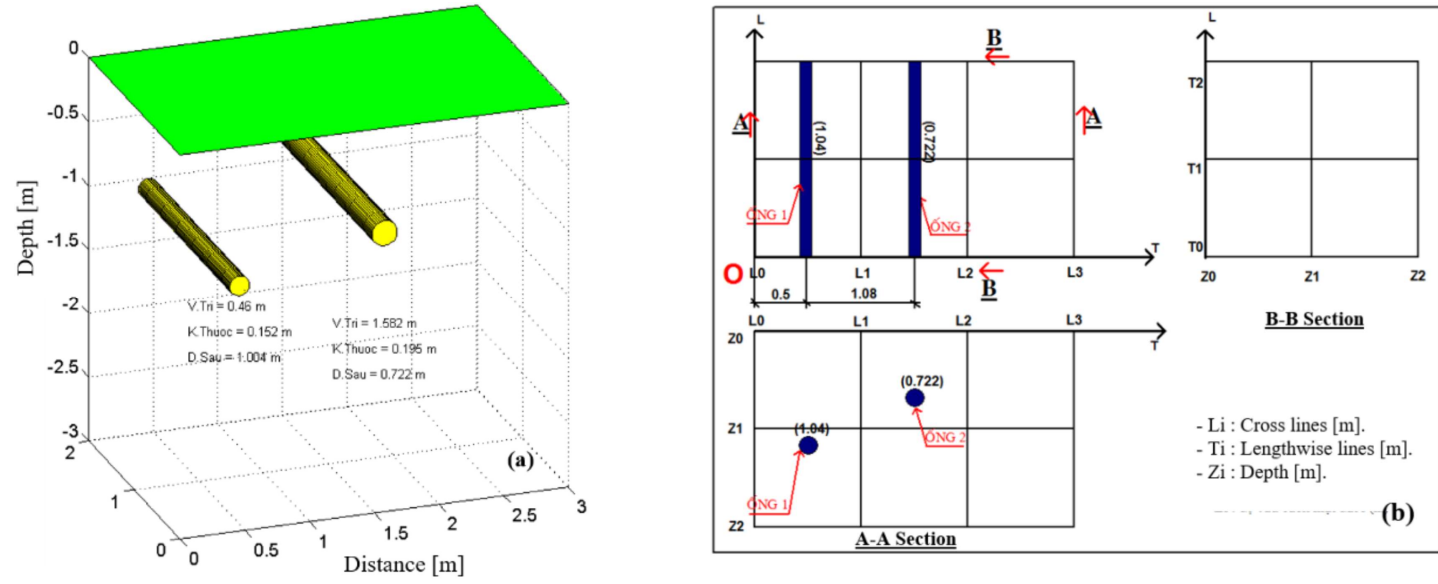

Fig. 11. Processing result: (a). 3D cross section; (b). Underground structure drawing

Colligating processing results, we established the underground construction drawing as Fig. 10b. This drawing provided completely position, size and the extension of not only the existing underground works but also the new underground works not included in as-built drawing. This result would supported specialist units remarkably in designing and installation new underground structures.

\section{CONCLUSION}

Construction process often caused a certain number of discrepancies between the design and execution. Therefore, to ensure the safety for the operator as well as the underground construction, using ground penetrating radar to locate the underground structure before drilling and digging was very necessary. However, it should be noted that GPR was affected significantly by electromagnetic properties of the survey area. Furthermore, GPR data interpreting requires specialist knowledge of data processing and experience as well as priori information about the survey area. Therefore, to apply successfully GPR to the management and maintenance mission, we had to have a human resource development plan in order to avoid wasting invested equipments as well as the limit confusion in data processing.

Our GPRTVN software could read multiple data formats, measured from many present GPR equipments in Vietnam: Detector Duo (IDS), Pulse Ekko (SENSORS \& SOFTWARE), Zond-12e (RADASYS). It integrated multiple filtering, amplification, migration (using energy and entropy diagram to define optimal migration section and correct velocity) so that the size and the depth of objects could be determined exactly. GPRTVN will support special units remarkably in designing and installation new underground structures in Vietnam.

\section{TÀI LIỆ THAM KHẢO}

[1] F. Bostanudin, Computational methods for processing ground penetrating radar data, $\mathrm{PhD}$ Thesis, University of Portsmouth, 2013.

[2] D. Flores-Tapia, S. Pistorius, "An entropy-based propagation speed estimation method for near-field subsurface radar imaging", EURASIP Journal on Advances in Signal Processing, vol. 2010, Article ID 636458, 13 pages, 2010.

[3] J. Gazdag, P. Sguazzero, "Migration of seismic data", Proceding of the IEE, vol. 72, pp. 1302-1315, 1984.

[4] J. Gazdag, P. Sguazzero, "Migration of seismic data by phase shift plus interpolation", Society of Exploration Geophysicistis, vol. 49, no. 2, pp. 124-131, 1984

[5] N.T. Van, N.V. Giang, "Ground Penetrating Radar Fundamentals and Applications", VNU Press, Ho Chi Minh, pp. 111-130, 2013.

[6] N.T. Van, N.V. Thuan, Đ.H. Trung, "Combining F-K migration and minimum entropy processing GPR data", Journal of Geology, no. 341-345, pp. 290-299, 2014.

[7] N.T. Van, N.V. Thuan, Đ.H. Trung, N.V.N. Lieu, V.M. Triet, N.T. Hoa, "Defined electromagnetic wave velocity by migration method, minimum entropy and energy diagram", Journal of Geology, no. 352-354, pp. 217-228, 2015.

[8] N.T. Van, N.V. Thuan, Đ.H. Trung, "Kirchhoff migration method and energy diagram in processing ground penetrating radar", Science \& Technology Development Journal, vol. 18, no. T5, pp. 42-50, 2015.

[9] O. Yilmaz, "Seismic Data Processing", Society of Exploration Geophysics, USA, 1987. 


\title{
Phần mềm xử lý dữ liệu ra đa xuyên đất GPRTVN
}

\author{
Nguyễn Thành Vấn, Nguyễn Văn Thuận, Đặng Hoài Trung, Võ Minh Triết, Võ Nguyễn Như Liễu \\ Trường Đại học Khoa học Tự nhiên, ĐHQG-HCM \\ Tác giả liên hệ: nvthuan@hcmus.edu.vn
}

Ngày nhận bản thảo 29-05-2017; ngày chấp nhận đăng 10-10-2018; ngày đăng 20-11-2018

Tóm tắt-Thiết kế và thành lập bản đồ công trình ngầm trong đô thị được thực hiện nhiều năm nay để đáp ứng nhu cầu cấp thiết trong xây dựng các công trình trong quá trình đô thị hóa. Để thực hiện điều này, phương pháp ra đa xuyên đất đã thể hiện những ưu việt khi xác định các đối tượng ngầm. Tuy nhiên, Việt Nam hầu như chưa có một chương trình xử lý nào đáp ứng được các yêu cầu xử lý và minh giải tài liệu GPR. Bài báo giới thiệu chương trình xử lý
GPRTVN, là kết quả nghiên cứu của Bộ môn Vật lý Địa cầu trong nhiều năm qua. Chương trình có thể xử lý nhanh dữ liệu của các máy GPR hiện nay và cung cấp mặt cắt công trình ngầm hiện hữu, phục vụ hiệu quả cho các công ty liên quan đến xây dựng và điều tra khảo sát công trình tại Việt Nam.

Tù khóa-entropy cực tiểu, năng lượng cực đại, dịch chuyển, xử lý dữ liệu GPR 